\title{
Organic farming and deforestation
}

To the Editor - We agree with Reganold and Wachter ${ }^{1}$ that organic farming offers lessons for improving agricultural sustainability. However, current organic certification systems do little to prevent deforestation and other forms of habitat conversion. For example, the USDA organic standard, widely applied around the world, failed to prevent deforestation for organic sugar in Paraguay ${ }^{2}$. The certification criteria recommended by the International Federation of Organic Agriculture Movements (IFOAM) specify that organic farms should not be established on "land that has been obtained by clearing of High Conservation
Value Areas in the preceding 5 years"3, but fail to elaborate how these areas should be identified, by whom, and how compliance is audited. Rigorous assessment of land-use change cannot be left to individual, poorly resourced auditors ${ }^{4}$. The organic movement must learn from other sustainability standards, such as the Roundtable on Responsible Soy and the Rainforest Alliance, which provide more rigorous protection for forests and other habitats. This will become increasingly pertinent as interest in finding ways to end habitat loss intensifies, and as companies commit to deforestation-free supply chains.
Cath Tayleur ${ }^{1 \star}$ and Ben Phalan ${ }^{2 \star}$ ${ }^{1}$ Conservation Science Group, Department of Zoology, University of Cambridge, David Attenborough Building, Pembroke Street, CB2 3QZ, UK. 'Department of Forest Ecosystems and Society, Oregon State University, Corvallis, Oregon 97331, USA. *e-mail:cmt43@cam.ac.uk; benphalan@gmail.com

References

1. Reganold, J. P. \& Wachter, J. M. Nature Plants 2, 15221 (2016).

2. Rogers, H. Mother Jones 35, 58-79 (2010).

3. The IFOAM Norms for Organic Production and Processing (IFOAM, 2014); http://bit.ly/21m1FOF

4. Jurjonas, M., Crossman, K., Solomon, J. \& Baez, W. L. World Dev 78, 13-21 (2016). 